\title{
CULTURAL DIVERSITY AND PEACEFUL COEXISTENCE: A REFLECTION ON SOME SELECTIVE SCHOOL TEXTBOOKS
}

\author{
Md. Touhidul Islam ${ }^{1}$ \\ Maria Hussain ${ }^{2}$ \\ S. R. Khan Orthy ${ }^{3}$
}

\begin{abstract}
Bangladesh adheres to the principles and values of respecting cultural, religious, and ethnic diversities and has enriched school textbooks for meeting demands of the society and preparing young generations as much as possible for future with adequate facts, well-known perspectives and diverse worldviews. School textbooks are one of the critical instruments of preparing young generations for future-with the values of respect, tolerance, mutual understanding, cooperation, unity, prosperity, partnership and humanity. However, sometimes textbooks could produce counter-productive outcomes if contents were not developed with well-thoughts and prudence. They also constitute a compulsion for a country to realise how the young children could be prepared with the values of maintaining and ensuring peace, accepting cultural diversity, and respecting the ethos of peaceful coexistence of multi-ethnic and multi-religious communities living in a society. As an elementary level effort, this paper has focused on some selective secondary level textbooks in Bangladesh to understand how the issues of cultural diversity and peaceful coexistence have been represented. There has been a plenty of textbook contents described and touched on the aspects of cultural diversity in various ways to enlighten students about pluralism and values of social cohesion. However, a more delicate and detailed presentation of some issues could help students socialisation process and of learning about respecting and accepting the diversity of all kinds better. Some more visual representations of diverse cultures and practices, and more practical tasks on valuing rights, dignity, tolerance, and empathy could benefit them further. Nonetheless, there is an
\end{abstract}

${ }^{1}$ Md. Touhidul Islam, PhD, Associate Professor, Department of Peace and Conflict Studies, University of Dhaka. Email: touhid.pacs@du.ac.bd

2 Maria Hussain, Assistant Professor, Department of Peace and Conflict Studies, University of Dhaka. Email: maria.hussain@du.ac.bd

${ }^{3}$ S. R. Khan Orthy, Research Assistant, Conflict and Resilient Research Institute Canada (CRRIC), Winnipeg, Manitoba, Canada. Email: skorthy@gmail.com

Social Science Review [The Dhaka University Studies, Part-D], Vol. 37, No. 2, December 2020 
essence of having skilled and qualified teachers who could play sincere roles in teaching such values in appropriate educational environments.

Keywords: culture, cultural diversity, peaceful coexistence, social cohesion, school textbooks

\section{Introduction}

Accepting cultural diversity is considered as one of the pre-requisites of maintaining peace and ensuring peaceful coexistence of communities living in multi-ethnic/religious societies. Culture in this process not only refers to the mere existence of a group but also indicates the exercises and practices of multiple languages, beliefs, habits, festivities, and many other components that make a condition for people of each group to live with others. To avoid any chaos, they also maintain a path of harmony and cohesion where multiculturalism prevails and is respected. However, there are many issues and concerns to which it needs attention to address them in culturally diversified societies. Under this broader perspective, this study focuses on school textbooks, which, as a part of the education system play an essential role in the daily lives of millions. Education is one of the main elements that helps to know about cultures of all segments of people living in a society and assists students in understanding the importance of each other's culture despite having differences amongst them. In a peaceful society, such diversities are mutually respected, and any problem once exposed is addressed with the principles which adhere that no one is superior or inferior to others regardless of gender, religion, ethnicity, and culture. Everyone is part of a culturally, ethnically, and religiously diverse society.

In principle, Bangladesh is a country that respects diversity, both in the religious and cultural aspects. Although the number of Muslim and Bangalee people is higher than any other religious and ethnic groups, all people have been living in broader society, one country, side by side for long. The ethos of multicultural norms and values is enshrined in the constitution of Bangladesh. Having these wider principles in consideration, we aim to understand the existing knowledge of cultural diversity and peaceful coexistence that school textbooks offer students for their basic knowledge gaining and developing them as persons of respecting such values. Therefore, we focus on school textbooks to explore such values that have been presented to and taught students of today for building a shared, peaceful society that leads them to esteem the values of respecting the 'others'. 
However, this is an exploratory qualitative study that has been conducted through an elementary content analysis process of some selected secondary level school textbooks. These include Bangla, Bangladesh and Global Studies and Religion (i.e., Islam and Moral Education, Hinduism and Moral Education, and Christianity and Moral Education) that are currently in use for teaching at classes of six to ten. These are standard books and approved by the National Curriculum and Textbook Board (NCTB). However, they have placed and focused on cultural diversity from different perspectives and enlighten students with various norms, values and socio-emotional skills required for maintaining harmony and social cohesion in a multi-ethnic and multi-religious society. For this study, some selective contents of these books have been clustered into groups for better understanding and analysis. We, moreover, conducted several expert interviews for a deeper understanding of related issues. These subjective interviews allowed experts to give meaningful and thoughtful insights into this study in an objective manner.

In the following section, we review primary literature of the concepts of culture, cultural diversity, and their connections to peaceful coexistence, as well as the issues of cultural pluralism in Bangladesh. After that, this paper sets to develop an analytical framework that examines the role of education, school textbooks and associated factors in terms of promoting cultural diversity and social cohesion. The fourth section discusses and reflects on the issues of cultural plurality, diversity and social harmony and coexistence presented in the school textbooks. The paper ends with some key conclusion points.

\section{Culture, Cultural Diversity, and Peaceful Coexistence: A Review of literature}

Quite a large number of literature have focused on culture and its dimensions; cultural diversity has got substantive attention in contemporary scholarly works of the conflict resolution field. Culture is significantly difficult, and a complex, term to be defined as this is an integrated concept related to social and individual constructions of people living in a society. One of the critical aspects of culture is that this is related to different groups, such as social, religious, economic, and political, meaning that this is an approach, behaviour or practice shared by the society or a particular group (Ferraro, 1998). Therefore, culture is considered as a combination of human knowledge, beliefs and behaviours, attitudes to each other, some shared values, feelings, goals, and attires which form a cultural/social group. Some essential elements of culture are language, economy and political 
patterns, interaction patters with others, style of life and manner of communication (Azimi, 2013). Culture neutrality may not exist because any development of social norms may privilege one conception over the others. Even the establishment of a minimalist libertarian state to foster as much cultural freedom as possible would fail to achieve true neutrality since such political philosophy could make some assumptions including that of not all cultures would accept equally (Mishra \& Kumar, 2014).

There are human differences so as in cultural perspectives that scholars acknowledge and realise in terms of addressing challenges, and exploring opportunities, connections, and scopes, of contentious issues that may arise due to cultural differences (Brigg \& Muller, 2009). Nevertheless, no population, as Avruch (1998: $18,20)$ argued that 'can be adequately characterised as a single culture or by a single cultural descriptor'; therefore, 'culture is to some extent always situational, flexible, and responsive to the exigencies of the worlds that individuals confront'. Some aspects of culture remain visible, whereas their meanings often are invisible. Hofstede (1991: 8) stated: 'their cultural meaning.... lies precisely and only in the way these practices are interpreted by the insiders', meaning such visibility and invisibility affect peoples' behaviour and one's interpretation attached to such attitudes and behaviours. Cultural diversity, nonetheless, in a society, is viewed as an opposition to monoculture practice that often tends to control and subjugate presence of diverse other cultures and practices.

The term' cultural diversity' means the presence of varieties of human societies or cultures in a specific region, within a country or across the world. Vossughi (2000) points out that cultural diversity includes language, race, sex, ethnic background, country or region of origin, dress, values, religion and associated practices, social and everyday responsibilities, sexuality, disability, notions of family responsibilities, political views and so on. One of the downsides of understanding cultural diversity is that people may understand cultures as heterogeneous but overlook 'intracultural diversity' (Avruch, 1998). Groups may have uniformity in many respects. These consider the cognitive, affective, and behavioural aspects, although any intracultural variation, either at the group or individual level, is seen as 'deviance', which perhaps makes a monocultural argument strong by synonymised culture with group identity (ibid). Once political scientist widely used the small-scale and socially embedded anthropological understandings of culture, the very core notion of culture has 
changed towards the 'political culture' and signposts like 'national character' added to the cultural and political lexicons (ibid). However, many of the contemporary conflicts and tensions are rooted and endured due to deep-rooted cultural differences, hatred, and prejudices towards the 'other' (Ramsbotham, Miall, \& Woodhouse, 2016). 'Cultural dissonance', as Bercovitch and ElgstrÖm (2001) argued, could lead to aggravating their relations as well as influence and affects parties' positions' in strategic conflict process. Not only labelling other people as the 'other', but culture can also be a source of 'respecting people's differences and avoiding assimilation and coercion' (Lin, 2019:2).

The term cultural diversity is synonymous of 'ethnic pluralism', but its core meaning is connected to 'equity and justice' (Lin, 2019: 4). Lin (ibid) argues: 'as cultural diversity is not just a reality of coexistence of diverse knowledge, beliefs, arts, morals, laws, customs, religions, languages, abilities and disabilities, genders, ethnicities, races, nationalities, sexual orientations, etc., of human beings, it is also extended to the way people react to this reality and the way people choose to live together with this reality'. However, one of the fundamental approaches of respecting cultural diversity is to recognise the 'others' so that people of other segments could live with dignity, meaning primary teaching for all to treating each other with respect and self-esteem (Bringham, 2001). Although recognition of other cultures could be seen as a courtesy, it has broader meanings and perspectives (like political, social, personal, and curricular recognition), which are indispensable for cultivating a sense of belongingness of all people (Taylor \& Gutmann, 1994; Bringham, 2001). The issue of recognition, however, is closely related to power, and the dominant group often holds such power to recognise the 'others' (Lin, 2019).

The second approach of cultural diversity emphasises on treating different groups, cultures, and segments equally. It carries a message of establishing a mental set up of all people irrespective of their cultures and identities that equally is not merely a moral obligation, instead is a practical issue that has to be reflected in the decision-making process (Rousseau, 1997). One, however, could argue that treating all people equally irrespective of their cultures could be unfair, especially when some cultures and its followers do not respect this value (Macedo, 2004). The third approach of cultural diversity states that the survival of humanity in the long-term by protecting minority groups, people and their cultures is crucial, which has close connections with the protection of 
biodiversity. If their cultures and identities are at risks, it is a priority of the state and policymakers to undertake such threats into account and make policies that redress not only past injustices but also undertake special arrangements for their advancements (Taylor \& Gutmann, 1994). This may create confusion with the principle of equality which under the circumstances could overlook the historical experience, inequalities, and atrocities that minorities faced much before the discourse of equality got prominence in theory and practice (ibid). Nevertheless, protecting cultures which are part and parcels of a wider society should be a priority of a country when some extremist groups want to reject values of inclusivity, togetherness, and gender equality (Lin, 2019).

To understand peaceful coexistence of multi-ethnic/religious communities what is primarily important is to consider peace as a complex 'social goal' that aims to achieve a condition of absence of violence, both its direct and structural forms (Galtung, 1969). In this complex process, all people irrespective of their identities and differences pursue to live together and maintain a cooperative relationship by avoiding any non-cooperative, hostile affairs which they may have. The movement of accepting diversity gained much attention in the $20^{\text {th }}$ century has witnessed the emergence of a cluster of intellectual and political movements. Such diverse groups like indigenous people, national minorities, ethnocultural nationals, old and new immigrants, feminists, and others led such movements. The commonality amongst those diversity movements is that there has been a plea for tolerance, respect, and acceptance of differences. As the possibility of disrespect, conflict and disharmony in a multicultural society is not unlikely, peaceful coexistence in such contexts implies the ability of humankind to accept diversity by rejecting their cultural, religious, and other prejudices, opposing interests and to live in harmony (Aziz, 2014). From a socio-cultural perspective, this coexistence of different groups is fundamental for maintaining the dynamics of society and pursuing well social interactions amongst them (Gregòri, 2014). Intercultural dialogue embodies such potential of peaceful existence, although there are some difficulties of such engagements. One of the key obstacles is to consider cultures as fixed. There are different fault lines exist amongst cultures that separate people and groups which they cannot overcome due to their confined, and conservative, worldviews that do not allow them to mix with others freely. When these are absolute, totalitarian ideologies or beliefs could also lead to confrontation amongst the cultures and could undermine the state of peacefulness (Kutukdjian \& Corbett, 2009). 
Considering Huntington's thesis of 'clash of civilisation', the risk at the global level is that one culture could become self-fulfilling. It presupposes itself as singular rather than multiple affiliations with other cultures, which could endanger cultural interdependency (Hungtington, 1996). However, the balance of cultures has found its way through time in a multitude forms of cultural customs and social practices which includes cultural exchanges, cultural borrowing, and cultural imposition (Kutukdjian \& Corbett, 2009). Generally, cultural exchange is a means of building friendly and mutually interdepend relations amongst cultures that could help to foster a culture of respect to the differences. Cultural borrowings are expressed when one group of the population embraces other cultures objectively. In modern cultural society, borrowing has become as persistent as challenging the distinction between endogenous and exogenous cultural elements. Cultural imposition, however, has many forms. From Western colonialization to present globalisation, cultural imposition has been a form of domination by the culturally influential groups, which tend to impose their values and patterns of behaviour to others (ibid). Even when the extreme condition of slavery or careful processes of reverse enculturation happened, dominating cultural practices forced others to assimilate (Bhabhna, 1994). The concept of 'equality' nonetheless sometimes could be used coldly to make minorities invisible, obstruct historical injustices and to maintain status quo, which may not allow better or worse treatment for them (Kennedy \& Hue, 2011; Seglow, 2003; Taylor \& Gutmann, 1994).

Bangladesh is an excellent example of practising multiculturalism and respecting cultural diversity. People of different religions and ethnicities living and sharing their values and norms. Their beliefs are different, and practices are so too, which are the foundation stones of accepting and recognising diversity in Bangladesh. Being predominantly a Muslim-populated state, Bangladesh also has Hindus, Christians, and Buddhists as well as multiple ethnic minority groups, which have made it indeed a diversified country, both religiously and culturally. Although religion influences peoples' cultural and historical development, Bangladesh in the post-independent phase started its journey as 'a secular polity with a constitutional embargo on religion in politics' (Samad, 1998). The 1972 Constitution of Bangladesh in Part II, Article 12 established the principle of secularism through the elimination of (a) any kind of communalism (b) any abuse of religion for political purposes and (c) any discrimination against or persecution of persons practising a particular religion (Ministry of Law, Justice and Parliamentary Affairs, 1972). As language movement 
was one of the key political factors of uniting people of Bangladesh, Bengali nationalism has influenced dealing with diverse linguistic and other minorities (Samad, 1998; Mohsin, 1997).

As interactions and conflicts between ethnic groups influence and determine their relationships, the nature of politics also shows how ethnicity contributes to the integrity of nationalities (Abedin, 2012). Since independence, the number of religious minorities has been declining from $23.1 \%$ in 1971 to $9.6 \%$ in 2018 (Minority Rights Group International, 2018). The state has not acknowledged the concept of 'indigenous' people, instead has recognised 27 ethnic groups as 'small ethnic minorities', although there are more than 50 ethnic groups in Bangladesh (ibid; Dhamai, 2014). Once in a programme, the then Chairman of the National Human Rights Commission stated that minorities, both ethnic and religious, are the most persecuted and oppressed population of Bangladesh (Hasnat, 2017). Nevertheless, what is crucial to establish a tolerant society is to allow every community to share their core values, celebrate their festivals and customs together. This also allows respecting others, because all traditions and religions or pseudo-religious beliefs are parts of people's everyday life. However, the ways the young people and future generations of a country are taught about such multicultural values, norms and accepting diversity that determines the extent of its social cohesiveness. In Bangladesh, education is divided into different streams like Bengali and English mediums, school, and madrasah, including the Alia and Qawmi systems. This has immense effects not only on dividing the young generations into different lines but also depriving them of numerous scopes of interactions required for reducing their gaps and respecting inclusivity (Rashid, 2017). Rahman and Islam (2012) argued that most of the social science and history textbooks contents taught students to respect human being irrespective of their ethnic or religious identity. Madrasah textbooks contents discriminated other religious groups, and English medium follows textbooks published from India and England, which to a considerable extent also created confusion due to lack of uniformity of the textbooks (ibid). The education system is the best way to build trust, improve the level of tolerance, understanding and cordial relationship with each other.

\section{Education: A Means of Promoting Cultural Diversity and Social Cohesion}

José Martí, in the eighteenth century, stated that 'education provides people with the keys to the world' (quoted in Salmi, 2006). Textbooks of educational 
institutions are one of the predominant sources of understanding cultural diversities a country adheres to in principle and practices. Textbook contents that are offered to students reflect about the country and the society, portrait, and project issues of respecting the diversities. Education is the best path of providing adequate understanding and knowledge and preparing an individual to grow with reasons and senses to live in a society and respecting rights, entitlements and freedoms of the 'others'. The knowledge of respecting diversity is vital because education affects students' self-perception and their views of their nation' as well as shapes' their image of others' (Roberts-Schweitzer, 2006:1). If they inculcate a 'negative image of "others"' at an early stage, this could exacerbate hatred, prejudice, social division, and violence, at worst, because they may lack critical thinking in everyday societies where inclusivity and equality are little practised (ibid). Therefore, providing fundamental education to all students irrespective of their differences is indispensable to meeting their basic needs as well as recognising them who they are. Representing issues of diversity in textbooks could be a challenge and an opportunity too.

The policymakers have to address claims of disadvantaged groups to ensure parity with other advanced groups and allowing such opportunity creates a condition for people to live with and learn about diversity, a pre-requisite of propelling economic growth and sustainable social development (Smith, 2006). Minorities, however, could develop a 'negative attitude' towards school especially when the parents do not speak the official language of the country, which in lieu could discourage other traditions than the mainstream one in the classrooms (Uemura 1999). Teachers could be disrespectful to linguistic and cultural diversities, too (ibid). Nonetheless, promoting social cohesion depends on the extent to which education is offered in a diversity sensitive manner and which in many ways meet conditions of fulfilling human needs, economic development, and socio-emotional demands of the students. Several indicators can connect all groups and segments of the population through education system like curriculum, textbooks, and teachers for ensuring their peaceful coexistence. Other factors like language, communication and cultural contents in education material are interlinked with those groups too (Kutukdjian \& Corbett, 2009). We focus on a few indicators like culture-based education, value-oriented education, psychosocial capacity and skill development, and peace education. These could inculcate students a subtle culture of respecting diversity and promoting social cohesion in multi-ethnic/religious societies (Caballero, 2009). 
The core of culture-based education is founded upon a system that reflects on societal, cultural diversity in the teaching process. Besides helping students to improve their knowledge of cultural and religious diversities a society often practices, it focuses on community-based knowledge, norms, and practices. It also represents indigenous groups, minorities and native structures in a way that reflects on their ways of believing, understanding, and letting others know about the core cultural components of each segment of the population (Kahumoku, 2014). A culture-based education, therefore, is designed to meet the academic needs of students to express and respect value differences that people of a society have (ibid). In a community of diversity, it could touch everything of diverse cultures and identities superficially but not going in-depth of anything, which in fact cannot contribute genuinely much to children's development of worldviews (Williams 2004). Value-based education, on the other hand, follows an approach that highlights more comprehensive and segmental values and norms underpinned in a society. As many communities may have pressures of 'longstanding prejudices and long-simmering conflicts', offering education service in such contexts may not always be 'value free' and could aggravate existing fragmentations (Roberts-Schweitzer, 2006:2). The ethos of value-focused education, therefore, has to be to create a conducive learning environment for all students. It encourages young generations to grow up together by respecting their different values, norms and practices, a pre-requisite of ensuring their peaceable coexistence, of embracing non-violence and of being self-disciplined (Salmi, 2006). When school textbooks contents misrepresent a segment or minority groups, such bias could lead to 'extreme reactions' of those groups because of the ignorance of their cultures and values (ibid:20). The way lessons on the history of a country are offered to students at schools and universities could be a source of either building friendly relations or exacerbating contentions with the 'other' [s] (Wallensteen, 2019). States' priority, therefore, remains to overcome any prejudices and to pay attention to representing all cultures in a manner that satisfies all segments and allows students to learn about social, moral, spiritual, and cultural values of the society.

Besides necessary skill development, socio-emotional capacity enhancement of student is a vital objective of the education system. As education contributes to improving children experience, expression and management of emotions, school textbooks proactively include contents that enhance their ability to establish positive, harmonious, and rewarding relations with other (Cohen, et al., 2005). 
The fundamental value of this cognitive development is to be more associated with others by developing a sense of reciprocal empathy. In a broader sense, this indicates the ability to understand own feelings and manage emotions in a constructive manner, which helps to regulate their behaviour and attitudes towards others, which is an imperative of previewing an optimistic worldview. A socio-emotionally developed person has some outstanding virtues, such as diligence, openness to experience, amicability and optimism for well-being, and positive emotional stability (OECD, 2017).

The fourth element of promoting social cohesion and cultural diversity is peace education, which, as a concept has significance to promoting peace and reducing the extent of violence (Agnihotri, 2017). Peace education mainly focuses on including some contents in the curriculum for making students aware of the 'utility of peace education'. The term 'education for peace', however, is holistic that aims to be applied 'in every aspect of educational endeavour and involving all stakeholders to achieve the desired results' (ibid: 913). The educationalists and policymakers of a country determine which types of education are required to address issues of social disparity, non-recognition, and injustice that their society has experienced (Cabedo-Mas, 2015). In such contexts, peace education promotes 'knowledge, skills, attitudes and values' for bringing behaviour changes that enable children, youth, and adults to prevent conflict and violence, both the overt and structural forms (Fountain, 1999:1). It also teaches how to resolve the dispute peacefully, and to create the conditions conducive to sustain peace at all levels.

In other words, this is a process of obtaining values and knowledge along with the development of attitudes, skills, and behaviour to live in harmony with others in a natural setting, whether it experiences conflict or not (Patra \& Mete, 2015; Cabedo-Mas, 2015). Apart from teaching skills of peaceful conflict resolution, this gives lessons to students and teaches about the inclusivity of different groups and promoting their human and civil rights. Without paying attention to broader issues of rights and dignity, individual's self-development cannot be fulfilled, and peace education may not be as productive as expected to ensuring pluralism in a society where different issues and factors influence complex social dynamics (Çıkılı \& Altınordu, 2020). School textbooks that emphasis on these issues help the students to understand and transform their misunderstanding in their own lives, and to other communities, to foster 'democratic values', both inside and 
outside the classroom, and thus to enhance practices of 'coexistence' of individuals and diverse segments of people (Cabedo-Mas, 2015: 79). Although violent behaviour could develop at an early stage, once 'positive social support' is provided to children through appropriate schooling that could reduce aggressive behaviour and contribute to ensure an affirmative role for promoting social cohesiveness, resecting diversity, and improving level cooperation amongst them (Hymel \& Darwich, 2018). Nevertheless, the effectiveness of textbook contents in terms of establishing a peaceful society depends on the extent to which students have the scope of exercising those value-oriented issues at the school and outside.

\section{Presentation of, and Reflection on, Cultural Diversity and Peaceful Coexistence in School Textbooks}

In the selective school level textbooks, we have found that broader issues of cultural plurality have been presented in diverse manners. Some of them are generic, while others are specific to religious dimensions and cultural contexts exist in Bangladesh. Although some books and chapters emphasised on religions and state-based nationalism, there are different other cultural issues that some other books included which allow the young students to know about diversity, to accept them and to show respects towards others. The issues and pointers of cultural diversity and peaceful coexistence of communities are considered and reflected based on main elements identified in the previous section.

\section{Culture-based education}

There are many contents included in different textbooks about the cultures existing in Bangladeshi society. In Bangla textbooks, for example, there are lessons of cultural traditions like teaching students about folklores, local cultures, and its history (NCTB, 2018b; 2017a; 2017b; 2017c). These help students to understand that these traditions and cultures are to be respected and preserved for social cohesiveness; for instance, the folklore culture has to be understood and saved before it disappears completely. Some books included contents on the 'Pahela Baishakh' (Bengali New Year celebration programme) (NCTB, 2017b: 70; 2017c: 116). This festival is not based on any religion, instead is a festival celebrated by people who are parts and parcels of Bangladesh. Festival like Pahela Baishakh is a part of national cultural identity, which inspires students to be respectful to all other local cultures and become more accepting of such 
celebrations, as discussed in the Social Science textbook of class seven (NCTB, 2018d: 17). Through stories like Pahela Baishakh, they learn that this festival has evolved over time but still is a unique one that has held and united people of diverse religions, races, cultures, and classes.

There is a story of rural beauty and culture in Bangla textbook of class eight named 'Rupai' (NCTB, 2017b: 118). This has portrayed the rural beauty and culture vividly that allows the students to feel more affectionate towards the countryside, its life, livelihood, and cultures. Textbooks contents that included stories of rural and urban cultures and lives, which to a great extent differ from each other, has merits for students to develop a more comprehensive worldview, required for respecting differences and building broader perspectives. There are other poetry or story lessons that have implied lessons of different cultures. Nevertheless, some stories at this early stage of life could influence students to become impatient to each other, if not hostile. In Bengali textbook of class nineten, there is a story named 'Banmanush' (NCTB, 2017c: 121) representing the life of wild people, which could be a tacit cause for some to think issues differently particularly in situations of stress and anxiety. Although local cultural and religious values in principle do not teach committing violence and promoting prejudices, stories like Banmanush perhaps carry a meaning noting but the primordial cave personalities. Bangla textbooks contents have presented in a way that teaches students about different cultures through stories and poetries, which have inner meanings about cultural values that students need to pick up with the assistance of qualified teachers to understand values of humanity, inclusivity, and respect.

Religion that constitutes a larger part of understanding and practising of culture and norms has immense effects on understanding and respecting diversity and previewing values of tolerance. In Islam and Moral Education textbook of class six, chapter 2 has explained how the neighbours, regardless of their religious orientations, should be treated. Religion talks about living in harmony, working together, side by side for maintaining a peaceful, tolerant, and humanitarian society (NCTB, 2017f: 77). This issue is also presented in the textbook of Christianity and Moral Education; chapter 9 of class six states that people should be respected irrespective of their race or religion.

The Social Sciences textbooks are better positioned to talk about differences, diversity, and acceptability. In every Social Science textbook, there are chapters 
describing Bangladeshi societal attributes and various cultures, like which groups of people consist of this society and various cultures they possess. They have also presented different cultures of ethnic minorities living in Bangladesh. However, the cultural practices of society could change. In Bangladesh and Global Studies textbook of class eight, how culture changes, and adjusting with other cultures to exist side by side is discussed (NCTB, 2018e: 35; ibid: 114). Several chapters of Social Science textbooks of class six to ten have discussed the socialisation process and on how people should live in harmony with people of diverse religions and cultures. These help students to abide by the norms of their religions and cultures, and to be more positive, sympathetic, and helpful to other groups, either religious or ethnic or gender orientation, for more significant causes of peaceful existence. Although socialisation process of different religious and racial groups could be different, students can learn about different indigenous groups, their lifestyles, their economy, religion, customs and cultural practices from different Bangladesh and Global Studies textbooks (ibid; NCTB, 2018d: 17; NCTB, 2018e: 35).

There is a combination of Bangalee and non-Bangalee, ethnic identity and cultures that have enriched the societal fabrics of Bangladesh (NCTB, 2018e: 114). There are stories related to 'ethnic minority' groups as the country does not acknowledge the term 'indigenous' to refer them. This inclusion and recognition of non-Bengali people to a great extent could be an enlightening approach that allows young students to know fundamental issues of who they are, what their lifestyles are and how they strengthened Bangladesh in various respects. Nevertheless, the issues of ethnic, cultural diversity, as argued by an academic (Interviewed on 25 July 2019), has not been detailed enough to understand sufficiently about the non-Bengali communities and people living in the country. Lessons and contents must focus on the 'equality of all the nationals', irrespective of their ethnicity, religion, and gender (ibid). Nationalism is a broad term that includes multiple identities and ethnic groups that must be taught students at an early stage so that they adhere to the concept of 'inclusivity', which embraces everyone regardless of their differences (An Academic, Interviewed on 05 August 2019).

For social cohesion amongst the diverse segments, students should learn more about cultural diversities of the society, which would allow them to express their ethnic identities and respecting others, both in ethos and practice so that no 
resentment grows amongst the identity groups. The way issues of ethnic minority and indigenous groups included may not allow all students at different levels to get a broader and full understanding of such population. They should get to know all ethnic, religious, and indigenous communities better than just to read about their generalised lifestyle and where they are located. Their distinctiveness from the majority community, festivals and different life and livelihood should be explicitly discussed and taught in schools as they are an inclusive part of diverse cultures present in Bangladesh. Respecting all cultural distinctiveness has to be well reflected and taught in a manner that encourages and pursues young generations to value all cultures irrespective of their divergences. Such respecting helps to build their identity stronger and improve their feelings of cultural belongingness in the broader national structures. An academic, who worked on the textbook contents, stated that children have delicate psychology (Interviewed on 05 August 2019). Therefore, it is vital to present contents in a simplistic manner rather than only including normative lessons that do not change meanings so that students can get a proper understanding of the subject and topic. Nationalism, for instance, could be defined broadly inclusive of diverse ethnicities so that all feel connected to nationalism and its elements in the history lessons, story lessons and others (ibid).

Bangladesh and Global Studies textbook of class nine-ten included contents that help students to be more responsible for learning and abiding by the rules, values, and customs. This helps to make them civic duty bearers of the societies and to become more tolerant and respectful to every ethnicity and religion (NCTB, 2017d: 187). However, culture is not a limited issue. There are various broader issues like the structures of family, its various forms, and socialisations process, social interaction amongst different groups where social values and family values play a vital role (ibid). All these have meanings to the construction of diversity and accepting and respecting them. Students, nonetheless, could be benefited from practical tasks, visual, colourful pictures of diverse communities and their cultural practices in the textbooks that could help them learn in different but creative ways, argued by an academic (Interviewed on 07 August 2019).

\section{Value-based education}

One of the key observations is that most textbooks have covered value-based contents in different lessons. From class six to ten, there are various lessons of values and how diverse values could help to build a better society. In Bangla 
textbooks, for example, there are stories of honesty and morality. There are lessons about great personalities like Prophet Muhammad (PBUH) (NCTB, 2017c: 73) and Mother Teresa (NCTB, 2018b: 39) who followed their actual values and norms for making a better world for humankind. The ways and approaches they followed carry a message for encouraging young students to serve people regardless of any differences they may have. Those lessons entail about sacrificing self-centred mentality and selfishness for capitalising more significant opportunities and scopes of building a peaceful society and inspire students to be positive. Lessons like 'Sukh' (Happiness) in Bangla textbook of class six teaches young minds to grow a mentality of respecting sensitivity where every person respects and values each other regardless of their nationality, religion, ethnicity and working-class (NCTB, 2017a: 68). There is a story, titled "Mamata dee" (Sister Mamata) in the Bangla textbook of class nine-ten about a maid who though was represented from a different class, the core meaning of it is to be respectful and tolerant towards people of all classes (NCTB, 2017c: 104). This has an inner meaning of self-respect, and everyone should be respectful to others. Students can also learn that every gender is vital to be treated equally and respectfully as the ideal meaning of equality between men and women is embedded in it. Nothing is more important than humanity, and every person irrespective of his/her position and status has an identity. The fundamental identity comes first is that all are human beings, then comes their cultural, religious, or ethnic identities (NCTB, 2017b: 81). The only purpose of education is not to make students literate but to awaken their humanity and humanly values is another moral objective of it.

Religion is one of the core sources of offering value-based education as each religion teaches people to their moral development, to be tolerant, honest, and respectful to each other. Islam and Moral Education textbooks have a chapter named 'Akhlaq' (Morality and Manners) that states in detail how to build one's moral character, to be a modest person, to respect others regardless of gender, religion, class, or race (NCTB 2018f:84; NCTB 2018g: 99). A chapter of Islam and Moral Education textbook of class seven has discussed the adverse effects of eve-teasing (NCTB, 2018g: 99) and teaches students that respecting women is an essential virtue of human life. Hinduism has emphasised on respecting women too. A lesson of Hinduism and Moral Education textbook of class seven shows that respecting women is fundamental; by following sacred scriptures, people should treat them equally (NCTB, 2017e: 23). In Christianity and Moral 
Education textbook, there is a chapter that talks about how students can remain mentally happy and be a right person, which concluded with a discussion of differences and equality between men and women for maintaining social peace (NCTB, 2015: 16). This has a message for young people to be tolerant, to learn the virtues of forgiving, a vital element of avoiding violence in social life. A chapter of Christianity and Moral Education textbook refers that people need to be in a good relationship with the others because they cannot live alone but need each other; therefore, they need to be involved in voluntary works (NCTB, 2017h: 16).

All religion-based textbooks describe how students should build their moral characters, to be more transparent, honest, and responsible and learning sympathy and empathy towards other people. Many social problems may originate due to the existence of diversity in classes, religions, ethnicities, which could be fought by the virtues of forgiveness, non-violence, honesty, and purity (NCTB, 2017h: 128). Although religion is a matter of belief and respecting others, sometimes it perhaps is hard to find the meanings of every lesson. Therefore, portraying a wider faith system and religious practices could encourage students about respecting multicultural/religious practices that have a critical perspective related to the forms of education. The textbooks that deal with faith systems and morality in different lessons should consider how best students could share their perspectives in building and sustaining inter-faith harmony.

Social Sciences textbook contents are another source of enriching students' valuebased education. These books open new horizons of understanding as the socialisation process teaches students many aspects, including to be respectful and to accepting others. From early childhood, a child learns to grow up in a family. Although children belong to diverse families, the basic unit of society, the fundamental values of human life are learnt at first at home (NCTB, 2018d: 31). In Bangladesh and Global Studies textbook of class eight, there is a broader discussion on socialisation, which explains differences between the rural and urban socialisation processes (NCTB, 2018e: 53). A chapter of Bangladesh and Global Studies of class nine-ten has discussed the depletion of social values and its consequences in society (NCTB, 2017d: 210). As a part of the socialisation process, discussion on matters and issues related to harmony, the interactive system of human lives is more required for the creation of a value-based society. Others like Bangla and religion-focused textbooks also put efforts to value-based 
education, put humanity at the forefront to build empathy and respecting others irrespective of having differences. Mentioning a phrase like "...regardless of gender, religion, ethnicity or class" at the end of a sentence, however, may not completely suffice all the necessary components of cultural and religious diversity that students could learn at their childhood and teenage. Students need to learn such diversities from practical perspectives. Although several lessons could help students to understand the facts and values of respecting pluralism, there should be more applied lessons on understanding and accepting diversity and treating people equally and with respect.

\section{Socio-emotional skill development}

Developing socio-emotional skills in early childhood is one of the ways to establish a future society respectful and tolerant of each other regardless of the differences that exist in a society. Some school textbooks emphasis on these issues to teach students to be more sympathetic towards others. Some lessons are designed to help students in understanding and developing socio-emotional skills. A story about a person who is physically challenged and mentally impaired would inspire students to be more respectful towards physically and mentally different people (NCTB, 2018b: 09). Learning on this is as crucial for young students as respecting them in a society that exhibits diversity. It matters less which culture they brought up, but what matter is that they grow up to be humans and live with others with sympathy and empathy (NCTB, 2017a: 06).

There is poetry titled "Jaago Tobe Aronyo Konyara" (Daughters of Mother Nature Awaken) in Bangla literature textbook of class eight (NCTB, 2017b: 130). The lesson reflects the idea of respecting and caring the helpless, deprived, and impoverished people, and of making students think more positively and being sympathetic to others. Developing socio-emotional skills meaning not only about respecting and caring others but also to improve thyself with the virtues of hardworking, patience, empathy, and tolerance. Suppose a person wants to succeed in life. In that case, a person has to improve continuously through hard working that is a message of the story "Uddyam o Parishram" (Enthusiasm and Diligence) presented in Bangla textbook of class nine-ten (NCTB, 2017c: 56). Great personalities could inspire students to be like them. Stories of them help young children to see the broader picture of the world and build a moral character for working to humanity regardless of any distinctions people may have (ibid: 73). Improving socio-emotional skills, in other words, means developing leadership 
skill and capacity of uniting people which is required not only to address adversities but also to work for inclusivity in reality. A lesson like "Bandh" (Embankment) helps students to understand the essence of qualities like hardworking, leadership and unity (ibid: 145). Many people need special assistance and care to live in a society that once students learn at an early stage, they could be respectful to them and to address their needs from early childhood.

There are several lesson contents in religious textbooks to inspire students to develop their socio-emotional skills. As mentioned earlier, a lesson in Islam and Moral Education textbook of class six titled 'Akhlaq' stated about neighbours which in essence teaches students how to behave nicely with their neighbours and others regardless of their religion, class, or nationality (NCTB, 2018f: 84-94). Moreover, different lessons on prayers help students to improve their qualities; for example, fasting helps to be more moderate, sympathetic to others and grow endurance (ibid: 37). Chapter four of the Islam and Moral Education textbook of class eight (NCTB, 2018h: 89) emphasises on people to be more tolerant. There are different groups of people coming from different cultures, religions, races, or ethnicities, and all deserve to be respected. This lesson teaches students to be more tolerant and respectful to their opinion and ideologies. These have a significant influence on students to respect others' opinion, and to be more tolerant, two essential pre-requisites of social cohesion and harmony. Christianity and Moral Education textbooks also focus on these qualities. The textbook of class seven, chapter nine points out how forgiveness, self-control and positive attitude to others could help everyone to build a peaceful society (NCTB, 2017g: 79). The importance of justice and associated issues were placed in a textbook for students to learn about justice and morality to exercise in a society and state (ibid).

Social Sciences textbooks like Bangladesh and Global Studies have brought a new dimension of developing socio-emotional skills. While the discussion was about different people of different cultures, religions, classes, or ethnicities, these included lessons to appreciate every kind of culturally diversified people located both in the urban and rural areas. Every student has to understand the economic, social, and cultural differences exist between the rural and urban areas as both economies are significant for the development of a country. When students have a clear understanding of cultural, economic, natural differences between these areas, they would learn not only to appreciate their contributions but also to feel 
visiting other regions to have more reliable, detailed understanding (NCTB, 2018c: 56). This is important for the children living in rural or urban areas to know the country, and for protecting the rights of indigenous and ethnic groups and communities living in different parts of the country. Their culture, language and religion should be practised by them without any caveats (ibid: 82). Society has different practising religions which should be abided by the norms of religious values, rituals, and respect. This teaches a child to grow up with values of respect and tolerance (ibid: 88). Chapter nine of the Civic and Citizenship of class nine discussed how to be respectful and tolerant in practice, and how to address any problems collectively, standing all people side by side (NCTB, 2018a: 97).

Socio-emotional skills like expressing sympathy and empathy, being positive and embracing inclusivity are essential for sustainable peace in a diverse society. Many of the lessons of school textbooks have tried to develop socio-emotional skills of students. However, students may not practically learn how to encounter something which is not supported by positive socio-emotional skills. For instance, there is a story in Bangla literature textbook of class nine-ten that has elucidated how riots could breach the peace of people (NCTB, 2017c: 121); but what measures could be undertaken in terms of addressing such situation need more attention. Learning about socio-emotional skills is different from developing a practical capacity for addressing social problems. Just mentioning what is right and what is incorrect may not be sufficient for secondary level students to deal with social problems and accepting other's opinion. With the knowledge and development of socio-emotional skills, they also need to learn how to deal with unpleasant incidents, tensions, and disputes in real life.

\section{Peace education}

The selected school textbooks in diverse ways focused on educating young students about values of peace, as discussed, the previous sub-sections. There are areas where some contents have presented issues and values of peace less explicitly. A story in Bengali literature textbook of class nine-ten titled "Upekkhito Shaktir Udbwadhan" has reflected the importance of being together for democracy, for which it has emphasised on for all people to be treated equally (NCTB, 2017c: 83). There are lessons of non-violence and rights. Religion and Moral Education textbooks have paid attention to issues of peace and tolerance too. Chapter three of class nine-ten Islam and Moral Education textbook, titled 
"Ibadat" (Prayer) has referred that education is related to morality (NCTB, 2018i: 117). It defies terrorism, as extremism brings consequences for society. Jihad is nothing like the way contemporary extremist groups have explained to motivate their followers. There is no relation between Jihad and extremism. Every Muslim should learn true Islamic history and exercise Islam as a religion of peace that does not cause harm to people of the other faiths. However, terrorism and extremism have been identified as pressing issues and projected that the depletion of social values and norms causes such illness. To prevent threats of extremism, all sections of people and the state need to work together so that this does not disturb social peace (NCTB, 2017d: 210).

Christianity and Moral Education textbooks have also defied violence. A chapter of the class nine-ten textbook titled "Paribortito Bishwa chai" has in details described what peace is about and how peace could be achieved (NCTB, 2017h: 128). By acknowledging the societal segments, diversity, and problems, it illustrates that people once work together and try to live in harmony with others by forgetting their differences, there would be more scopes and spaces for practising forgivingness, non-violence, and purity (ibid). Hinduism and Moral Education textbook of class nine-ten has also projected that all people are connected; therefore, harming others means harming one-self (NCTB, 20181: 109). All should be cooperative with each other and live a peaceful life with others, connecting the society and each community (ibid).

Bangladesh and Global Studies textbooks teach students about peace education as these provide basic knowledge of civic duty and rights of every citizen living in a multi-ethnic/religious society. There are chapters on the qualities of a good citizen, although education for peace is not limited to this knowledge but covers various issues of societal values too. The aged people, for example, have many problems. A chapter of class seven has discussed how to address such concerns and help them (NCTB, 2018d: 86). The role of women in society is also discussed and elaborated. Besides emphasising on their rights and empowerment issues, it highlights the discriminatory practices women face in society and talks about how best such practices could be changed (ibid). Another chapter of this textbook has introduced students with different societal problems like superstition, early marriage and then discussed how to address such issues (ibid: 96). In each Social Science textbook, there is at least a chapter entitled to deal with the social problems and ills and urged to increase social awareness amongst citizens, 
including students, to prevent and address them. Politics and Citizenship textbook of class nine-ten has introduced the issues of civic rights and duties of students. Chapter three of it has referred to issues of the rule of law, meaning that laws are the same for everyone regardless of identity, religion, class and race, gender, rich or poor (NCTB, 2018a: 22). For a peaceful civil life, there is a need of democracy, good governance and social values, and education for peace allows students to know about broader ideas, political philosophies and politics of the country that have significance for maintaining social harmony and peace.

Some textbook contents have referred to avoid conflicts. However, how such a situation of crisis could be handled as a part of broader peace activities that promote and respect others, value cultural norms and handle the situation appropriately that has to be more prioritised. As a part of this, cultural diversities could sometimes face obstacles. Cultural exchanges could go wrong sometimes when students are not well aware with the cultural values, norms, and practices of other segments. Students, therefore, should be prepared for addressing everyday life problems through their knowledge of civil rights, understanding of valuing others and the responsibilities of good citizens. Teaching like 'not to get angry or rough at other people from different culture' is a notable example in this regard (NCTB, 2017f: 77). However, lessons about explaining why and how to avoid such vulnerabilities and issues would demand more understanding and engagements so that students could learn some fundamental techniques of the conflict resolution process too.

\section{Scope of practical engagement}

Practical exercise of something could ensure a profound understanding of knowledge. In textbooks, there are group works after some lessons that allow students to form different teams to work on what they have learnt so far. For example, after learning about the cultures of Bangladesh, students could sit in a group, and their first group work is to find out the components of the national culture (NCTB, 2018c: 51). Second group work is set to familiarise with Bangalee culture and visualise through a cultural program (ibid: 51). Through such group works, they could reflect on their knowledge and perform through cultural performance. One could question the extent to which students of small ethnic communities and minorities could represent their cultures to other students who may have little understanding about broader society, ethnic groups and their culture, customs, and practices. All Social Science textbooks from class six to 
ten, such group works are included after the lessons. Bangla literature textbooks have included 'কর্ম অনুশীলন' (practice task) after each lesson for each student. Such tasks could be done individually or collectively.

There is a story of 'Rokeya Shakhawat Hossain' who principally and philosophically inspired women for pursuing education, career and for empowering themselves. After this lesson, the practical task for students is to write an essay about a woman in their life (mother, sister, teacher etc.) who is pursuing a career and to be inspired from a real character of their life (NCTB, 2017a: 46). Religion-based textbooks also included some practical tasks. After a lesson of learning about respecting and valuing neighbours in Islam and Moral Education textbook of class six, students have a task to write down five sentences about the importance of having a good relationship with their neighbours (NCTB, 2018f: 85). In Hinduism and Moral Education textbooks, after learning stories about honesty and morality, students' task is to write down their ideas on honesty, morality. It also includes writing the names of some honest people that they know of, which could help them to learn and to become passionate, to be honest like them (NCTB, 2017e: 48). Christianity and Moral Education textbooks are no different in this regard. After the lesson of social justice and its importance in society, their task is divided into group works. It asks them to find out sectors of a society, where justice is present and where it does not. After preparing this work in a poster, their task is to present in front of everyone and share their views with others (NCTB, 2017g: 80).

These types of group work create scopes for students doing practical tasks and share their thoughts with others that have significance for broadening their worldviews required for peaceful coexistence. However, there has been an abundance of individual task. Many of them, if not all, if possible, to accomplish in groups could help students bringing together and improve their collective understanding. An academic expert (Interviewed on 25 July 2019) argued that the lessons could have been more benefited if there were more details of such practices that allow students to learn by acts. Another academic (Interviewed on 16 February 2019), however, argued that it may not always be possible to follow the group work sessions as there are many students in a class that sometimes could not be possible to manage within the limited time of the class slot. ${ }^{8}$ Ensuring quality education is only possible when the students do not take lessons 
as burdens, argued by another academic (Interviewed on 07 August 2019). A suitable, friendly environment is vital for a student to learn practically, wherein teachers are the key resources who can teach lessons in a meaningful way and with a broader worldview. Without qualified teachers, all the process of teaching accepting diversity, respecting others' opinion, views, and rights could not be flourished (ibid).

\section{Conclusion}

Once Maria Montessori stated, 'Those who want war prepare young people for war; but those, who want peace have neglected young children and adolescents so that they are unable to organise them for peace' (quoted in Agnihotri, 2017: 913). Maintaining social cohesion and harmony in a multi-ethnic and religious society requires embracing diversity and pluralism. School textbooks, to a considerable extent, contribute to preparing young generations in terms of accepting cultural and other diversities. Without respecting diversified cultural norms and values, students of today may not be adequately prepared for a shared future that embraces diversity. In this elementary study on some selected secondary level textbooks, we argue that there has been plenty of contents related to respecting diversity, which immensely can contribute to enlighten students about cultural diversity and pluralism. They can be familiarised with different cultures, and religions exist in Bangladesh. Such contents have the potential to create future generations that respect pluralism, although there are scopes of a more delicate, detailed, and thorough presentation of some issues of diversity.

A significant number of contents and lessons certainly helps students' upbringing and socialisation process in a manner that allows learning to respect others' opinion and views. Students spend an extended period of their time in schools. They intermingle with others who often come from diverse socio-economic and cultural backgrounds that enrich their socialisation process and views of respecting diverse cultures, customs, and practices. Nevertheless, only introducing different culture and traditions, and ask them to accept it may not be adequate. It instead may require more to learn about valuing and respecting diverse cultures, value systems including rights, dignity, tolerance, and empathy in practice - not only in individual exercise but also collectively, which has been prioritised in a limited nature. There are scopes to do elaborative and rigorous 
studies to undertake any revision of the contents. This process could consider the concept of inclusively more broadly that may help to improve the sense of respecting diversity amongst the future generations. Nevertheless, there is an essence of having adequately skilled and qualified teachers to offer lessons on diversity, social cohesion, and harmony.

\section{Acknowledgements}

This research was carried out with generous supports of ActionAid Bangladesh. We acknowledge the contributions and suggestions of different stakeholders provided in this study at different stages.

\section{References}

Abedin, N. (2012). Impact of ethnicity on national integration: A comparative perspective, Journal of the Asiatic Society of Bangladesh, 57(1), 1-27.

Agnihotri, S. (2017). Critical reflection on the role of education as a catalyst of peace-building and peaceful coexistence, Universal Journal of Educational Research, 5(6), 911-917.

Avruch, K. (1998). Culture and Conflict Resolution. Washington, D.C.: United States Institute of Peace Press.

Azimi, M. (2013). Cultural diversity: An overview, International Journal of Asian Social Science, 3(10), 2147- 2151.

Aziz, E. A. (2014). Peaceful coexistence in the right way. The Star. Retrieved from https://www.thestar.com.my/opinion/columnists/ikim-views/2014/09/16/ peaceful-coexistence-the-right-way/ (Accessed on 14 June 2019).

Bercovitch, J., \& Elgstrom, O. (2001). Culture and international mediation: Exploring theoretical and empirical linkages, International Negotiation, 6(1), 3-23.

Bhabhna, H. K. (1994). The Location of Culture. London and New York: Routledge.

Brigg, M., \& Muller, K. (2009). Conceptualising culture in conflict resolution, Journal of Intercultural Studies, 30(2), 121-140.

Caballero, M. J. (2009). Convivencia escolar: Un estudio sobre buenas prácticas, Instituto de la Paz y los Conflictos, 03, 154-169.

Cabedo-Mas, A. (2015). Challenges and perspectives of peace education in schools: The role of music, Australian Journal of Music Education, 1, 76-86.

Çıkılı, D., \& Altınordu (2020). Expansion of the right to education, In: Korkmaz, Zeynel; Winker, Michael and Mührel, Eric (Eds.) Extension of Human Rights to Education, PoliTeknik: Germany, 94-99.

Cohen, J., Onunaku, N., Clothier, S., \& Poppe, J. (2005). Helping Young Children Succeed: Strategies to Promote Early Childhood Social and Emotional Development. Washington DC: National conference of state legislatures.

Dhamai, B. M. (2014). An overview of indigenous peoples in Bangladesh. In: Mong Shanoo Chowdhury (Ed.) Survival under Threat: Human Rights Situation of Indigenous Peoples in 
Bangladesh. Chiang Mai \& Dhaka: Asia Indigenous Peoples Pact and Kapaeeng Foundation, 10-26.

Ferraro, G. (1998). The Cultural Dimension of International Business. New Jersey: Pretice Hall.

Fountain, S. (1999). Peace Education in UNICEF. New York: UNICEF.

Galtung, J. (1969). Violence, peace, and peace research, Journal of Peace Research, 6(3), 167-191.

Gregòri, S. P. I. (2014). Types of factors in educational peaceful coexistence, American Journal of Educational Research, 2(2), 84-96.

Hasnat, M. A. (2017). Religious and ethnic minorities are the most persecuted in Bangladesh, Dhaka Tribune. Retrieved from https://www.dhakatribune.com/bangladesh/law-rights/ 2017/12/28/religious-ethnic-minorities-persecuted-bangladesh/ (Accessed on 15 May 2019).

Hofstede, G. (1991). Cultures and Organisations: Software of the Minds. London: Harper Collins Business.

Hungtington, S. P. (1996). The Clash of Civilisation: Remaking the World Order. New York: SIMON \& SCHUSTER.

Hymel, S., \& Darwich, L. (2018). Building peace through education, Journal of Peace Education, 15(3), 345-357.

Kahumoku, D. W. (2014). Culture Based Education. s.1.:Kamehameha Schools.

Kennedy, K. J., \& Hue, M. T. (2011) Researching Ethnic Minority Students in a Chinese Context: Mixed Methods Design for Cross Cultural Understandings. Comparative Education, 47(3), 343-354.

Kutukdjian, G., \& Corbett, J., (2009) Investing in Cultural Diversity and Intercultural Dialogue, s.l.: UNESCO Publishing.

Lin, C. (2019) Understanding Cultural Diversity and Diverse Identities, In: W. Leal Filho et al. (eds) Quality Education, Encyclopedia of the UN Sustainable Development Goal, (929-938) Switzerland: Springer.

Macedo, S (2004) Liberalism and Group Identities. In: McDonough, K., \& Feinberg, W. (Eds.) Education and Citizenship in Liberal-democratic Societies: Teaching for Cosmopolitan Values and Collective Identities. (414-436). Oxford: Oxford University Press.

Ministry of Law, Justice and Parliamentary Affairs (1972) The constitution of the People's Republic of Bangladesh. Dhaka: Ministry of Law, Justice and Parliamentary Affairs, Government of Bangladesh.

Minority Rights Group International (2018) World Directory of Minorities and Indigenous Peoples: Bangladesh. Minority Rights Group International. Retrieved from https://minorityrights.org/ country/bangladesh/ (Accessed on 09 May 2020).

Mishra, S., \& Kumar, C. B. (2014). Understanding Diversity: A Multicultural Perspective. IOSR Journal Of Humanities And Social Science, 19(09), 62-66.

Mohsin, A. (1997) The Politics of Nationalism: The case of the Chittagong Hill Tracts, Bangladesh. Dhaka: The University Press Limited.

National Curriculum and Textbook Board (NCTB) (2018a). পৌরনীতি ৫ নাগরিকতা : নবম-দশম শ্লেণি (Civics and Citizenship: Class Nine-Ten). Dhaka: National Curriculum and Textbook Board.

NCTB (2018b). চারস্থপাঠ : বर्ঠ ब্রেণি (Bangla Literature Textbook: Class Six). Dhaka: National Curriculum and Textbook Board.

NCTB (2018c). (Bangladesh and Global Studies: Class Six). Dhaka: National Curriculum and Textbook Board. 
NCTB (2018d). বাংলাদেশ ও বিশ্বসরিচয় : সঙ্ত্ শ্রেণি (Bangladesh and Global Studies: Class Seven). Dhaka: National Curriculum and Textbook Board.

NCTB (2018e). বাংলাদেশ ও বিশ্বসরিষ্য় : অষ্ম শ্রেণি (Bangladesh and Global Studies: Class Eight). Dhaka: National Curriculum and Textbook Board.

NCTB (2018f). ইসলাম ও নৈতিক শিড়াগ : ষর্ঠ ল্রেণি (Islam and Moral Education: Class Six). Dhaka: National Curriculum and Textbook Board.

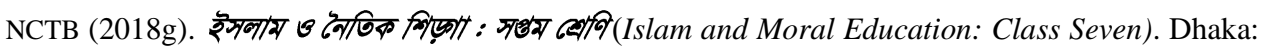
National Curriculum and Textbook Board.

NCTB (2018h). ইসनাম ৫ নৈতিক শিড়শা : অষ্ম ল্রেণি(Islam and Moral Education: Class Eight). Dhaka: National Curriculum and Textbook Board.

NCTB (2018i). ইসলাম ৫ নৈতিক শিড়াগ : নবম-দশম ল্রিণি(Islam and Moral Education: Class Nine-Ten). Dhaka: National Curriculum and Textbook Board.

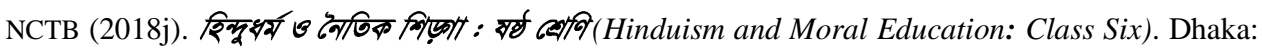
National Curriculum and Textbook Board.

NCTB (2018k). रिन्্ूरর্ম ৫ নৈতিক শিড়শা : অষ্টম শ্রেণি (Hinduism and Moral Education: Class Eight). Dhaka: National Curriculum and Textbook Board.

NCTB (20181). হিন্দুর্ম্য ও নৈতিক শিড়াগ : নবম-দশম ল্রেণি(Hinduism and Moral Education: Class NineTen). Dhaka: National Curriculum and Textbook Board.

NCTB (2017a). সঞ্চবর্না : সপ্ত্য শ্রিণি (Bengali Literature Textbook: Class Seven). Dhaka: National Curriculum and Textbook Board.

NCTB (2017b). সাহিত্য কণিকা : অষ্ম ল্রেণি(Bangla Literature Textbook: Class Eight). Dhaka: National Curriculum and Textbook Board.

NCTB (2017c). বাংলা সাহিত্য : নবম-দশম শ্লেণি (Bangla Literature Textbook: Class Nine-Ten). Dhaka: National Curriculum and Textbook Board.

NCTB (2017d). বাংলাদশ ৫ বিশ্বপরিচয় : নবম-দশম শ্রেণি (Bangladesh and Global Studies: Class NineTen). Dhaka: National Curriculum and Textbook Board.

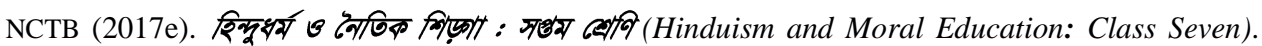
Dhaka: National Curriculum and Textbook Board.

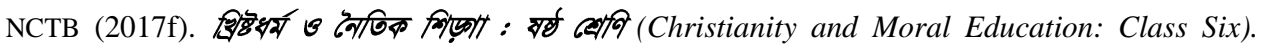
Dhaka: National Curriculum and Textbook Board.

NCTB (2017g). প্রিষ্মর্ম ও নৈতিক শিড়শ্গ : অষ্ম শ্রেণি (Christianity and Moral Education: Class Eight). Dhaka: National Curriculum and Textbook Board.

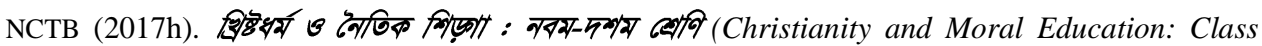
Nine-Ten). Dhaka: National Curriculum and Textbook Board.

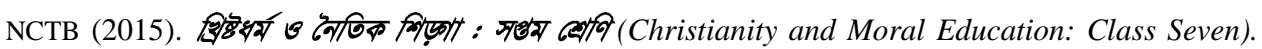
Dhaka: National Curriculum and Textbook Board.

OECD (2017). Social and Emotional Skills: Well-being, connectedness and success, s.1.: OECD.

Patra, J. N., \& Mete, J. (2015). Peace education in the 21st Century.In Jana, R.K. (Ed.) Modern Trends in Education. New Delhi: APH Publishing Corporation.

Rahman, M. M., \& Islam, M. T. (2012) Religious Morality in Social Science Textbooks for Class III and VII at Different Types of School: A Review. Social Science Review [The Dhaka 
University Studies, Part-D], 29(1), 135-148.

Ramsbotham, O., Miall, H., \& Woodhouse, T. (2016). Contemporary conflict resolution, $6^{\text {th }}$ Edition, Oxford: Polity.

Rashid, S. (2020) Dividing education is dividing culture. The Financial Express. Retrieved from $\mathrm{https}$ ///thefinancialexpress.com.bd/views/dividing-education-is-dividing-culture-1509733761 (Accessed on 16 May 2020).

Roberts-Schweitzer, E. (2006) Introduction, In Roberts-Schweitzer, E., Greaney, V., \& Duer, K. (eds.) Promoting Social Cohesion through Education: Case Studies and Tools for Using Textbooks and Curricula, (1-5). Washington D.C.: The World Bank.

Rousseau, J. J. (1997) The Social Contract and Other later Political Writings. Cambridge \& New York: Cambridge.

Salmi, J. (2006) Violence, Democracy, and Education: An Analytic Framework. Suffer The Little Children (Advances in Education in Diverse Communities, Volume 4). Emerald Group Publishing Limited, 207-230.

Samad, S. (1998) State of Minorities in Bangladesh: From Secularism to Islamic Hegemony, paper presented at Regional Consultation on Minority Rights in South Asia, held on 20-22 August 1998 at Kathmandu, Nepal.

Seglow, J (2003) Neutrality and Equal Respect: On Charles Larmore's Theory of Political Liberalism. The Journal of Value Inquiry, 37(1), 83-96.

Smith, A. (2006) Education for Diversity: Investing in Systemic Changes through Curriculum, Textbooks, and Teachers, In Roberts-Schweitzer, E.; Greaney, V. \& Duer, K. (eds.) Promoting Social Cohesion through Education: Case Studies and Tools for Using Textbooks and Curricula, (29-43). Washington D.C.: The World Bank.

Taylor, C., \& Gutmann, A (1994) Multiculturalism: Examining the Politics of Recognition. Princeton: Princeton University Press.

Uemura, M. (1999). Community Participation in Education: What do we know? (No. 24670, p. 1). The World Bank.

Vossughi, H. (2000). An encyclopedic dictionary of teaching english as a foreign language. Tehran: RahmanaPublications.

Wallensteen, P. (2019) Global Conflict, Autonomous Agreements and the Challenge of Quality Peace, In Rahman A.K.M.A. (ed.) Bangladesh in International Peacebuilding: Discourses from Japan and Beyond, Dhaka: Pathak Shamabesh.

Williams, M. (2004) Citizenship as Identity, Citizenship as Shared Fate, and the Functions of Multicultural Education. In McDonough, K. \& Feinberg, W. (eds.) Education and Citizenship in Liberal-Democratic Societies: Teaching for Cosmopolitan Values and Collective Identities. (208-247) Oxford University Press, Oxford. 